\title{
Mitochondrial gene expression in the liver and muscle of high and low feed efficiency Japanese quail layers subjected to different environmental temperatures
}

D.M. Voltolini ${ }^{1}$, A.P. Del Vesco ${ }^{1}$, E. Gasparino ${ }^{1}$, S.E.F. Guimarães ${ }^{2}$, A.R. Oliveira Neto ${ }^{3}$, E. Batista ${ }^{1}$ and A.P.S. Ton ${ }^{1}$

${ }^{1}$ Departamento de Zootecnia, Universidade Estadual de Maringá, Maringá, PR, Brasil

${ }^{2}$ Departamento de Zootecnia, Universidade Federal de Viçosa, Viçosa, MG, Brasil

${ }^{3}$ Evonick-Degussa Brasil, São Paulo, SP, Brasil

Corresponding author: E. Gasparino

E-mail: egasparino@uem.br

Genet. Mol. Res. 13 (3): 4940-4948 (2014)

Received May 27, 2013

Accepted November 10, 2013

Published July 4, 2014

DOI http://dx.doi.org/10.4238/2014.July.4.8

\begin{abstract}
We evaluated the adenine nucleotide translocator (ANT) and cytochrome oxidase subunit III (COX III) mRNA expressions in the muscle and liver of Japanese quails presenting high and low feed efficiency (FE), and subjected them to three different environmental temperatures: comfort, heat stress $\left(38^{\circ} \mathrm{C}\right)$, and cold stress $\left(10^{\circ} \mathrm{C}\right)$. ANT mRNA expression was lower in the liver of heat-stressed animals. In the muscle, higher ANT and COX III mRNA expressions were observed in high-FE and cold-stressed animals. In the liver, much higher expression of COX III mRNA was observed in cold-stressed animals. These results suggest a possible correlation between the genes involved in energy production by the mitochondria and FE phenotypes, and that environmental temperature can affect the ANT and COX III mRNA
\end{abstract}


expressions. Japanese quails presenting different FE levels respond differently to environmental stimuli.

Key word: ATP; Cold stress; Feed efficiency; Heat stress; Mitochondria

\section{INTRODUCTION}

The mitochondria are the organelles responsible for transforming the chemical energy from metabolites into energy that can be easily accessed by the cell, and are responsible for producing $90 \%$ of the energy required by cells (Bottje et al., 2006). This energy is accumulated in labile compounds, the main one being ATP (Schauss et al., 2010). The free energy generated by the transport of electrons passing through the mitochondrial respiratory chain until reaching the ultimate acceptor, $\mathrm{O}_{2}$, is used to produce ATP from ADP + Pi. The electron transport system is a chain of enzymatic and non-enzymatic compounds, whose function is to transport high-energy electrons. This energy is provided for the complexes of the chain where ATP will be produced. The mitochondrial enzymes involved in oxidative phosphorylation are positioned in the inner membrane of the organelle, and are arranged in five multi-protein complexes (Nelson and Cox, 2008).

Recent studies have shown an association between the feed efficiency (FE) and energy production efficiency of mitochondria. Animals that are more efficient in converting feed to body weight display alterations in the expression of electron transport chain genes, which can influence the use of nutrients and alter the body's energy consumption. Furthermore, animals with higher residual feed intakes may suffer failure in the transport of electrons/protons, thus reducing the efficiency of ATP production by the mitochondrial genes, which has an adverse effect on the feed conversion process (Iqbal et al., 2005; Krueger et al., 2007; Bottje and Carstens, 2009).

Adenine nucleotide translocator (ANT) and cytochrome oxidase subunit III (COX III) are two other proteins that are involved in energy synthesis. ANT is responsible for moving ADP from the cytosol to the mitochondria and through the inner mitochondrial membrane (Ojano-Dirain et al., 2007). The mitochondrial function may be impaired by the incapacity of ADP/ATP exchange between the cytosol and the membrane; thus, there may be some connection between the ANT expression level and phenotypic expression of FE (Bottje et al., 2006). COX III is also present in the electron transport chain and is related to the oxidative phosphorylation efficiency because it is responsible for pumping protons and transporting electrons. Lower expression of these genes can occur due to lower cellular efficiency or greater oxidative damage due to the production of reactive oxygen species (ROS) (Kemp et al., 2003).

ROS are normally produced during cellular biological processes. At increased levels, ROS are frequently associated with events such as apoptosis, protein oxidation, lipid peroxidation, and mitochondrial DNA damage (Moustafa et al., 2004; Lee and Wei, 2005). An imbalance between the production and elimination of ROS in an organism leads to a state known as oxidative stress. Several studies have demonstrated correlations between heat stress and oxidative stress (Mujahid et al., 2005, 2009), and the effects of heat stress are suggested to be due to acceleration in the rate of ROS formation and/or an increase in ROS reactivity (Bai et al., 2003).

Besides high temperatures, the increase in energy requirements when animals are subjected to low environmental temperatures results in changes in the circulatory system in order to achieve these higher energy demands (Blahová et al., 2007). The blood concentration of the T3 hormone appears to be involved in the regulation of growth rate as a function of low 
environmental temperature. Blood T3 concentrations were negatively correlated with environmental temperature and were positively correlated with feed intake (Yahav, 2000).

This study was performed under the hypothesis that the genes involved in energy production by mitochondria may be related to the FE phenotype observed in poultry, and that the environment to which these animals are exposed could affect the expression of such genes. Thus, we evaluated the ANT and COX III mRNA expressions in the muscle and liver of Japanese quails presenting high and low $\mathrm{FE}$ and submitted each of these groups to three different environmental temperatures: comfort $\left(25^{\circ} \mathrm{C}\right)$, heat stress $\left(38^{\circ} \mathrm{C}\right)$ for $12 \mathrm{~h}$, and cold stress $\left(10^{\circ} \mathrm{C}\right)$ for $12 \mathrm{~h}$.

\section{MATERIAL AND METHODS}

The experimental procedure was approved by the Brazilian Animal Ethics Committee. The experiment was conducted on the Iguatemi Experimental Farm of the Universidade Estadual de Maringá (UEM). A total of 400 Japanese quail layers derived from the same breeder flock were reared until 28 days of age according to conventional management practices, and were subjected to the same experimental conditions. On day 28 , birds were transferred to individual cages in an environmentally controlled room and were submitted to a 7-day adaptation period. The FE was evaluated during the period of 35 to 42 days of age, and was calculated by the increase in body weight relative to the consumption of food. Birds were individually weighed at the beginning and at the end of this period to calculate body weight gain, and feed intake was calculated as the difference between the amount of feed offered and the feed residues at the end of this period. Birds were offered water and feed ad libitum during the entire experimental period. Feed was formulated to supply the Japanese quails' nutritional requirements, according to Rostagno et al. (2011). A two-stage feeding program was adopted, with a starter diet offered between 1-14 days, and a grower diet offered after 15 days of age. At 42 days of age, birds were divided in groups with high $(\mathrm{N}=36)$ or low $(\mathrm{N}=36) \mathrm{FE}$, and were submitted to three different environmental temperatures: comfort $\left(25^{\circ} \mathrm{C}\right.$, according to Pinto et al., 2003), heat stress $\left(38^{\circ} \mathrm{C}\right)$ for $12 \mathrm{~h}$, or cold stress $\left(10^{\circ} \mathrm{C}\right)$ for $12 \mathrm{~h}$. Twelve high FE quails and 12 low FE quails were subjected to each thermal environment.

After the stress period, birds were sacrificed by neck dislocation, and breast muscle (pectoralis superficialis) and liver samples were collected and stored in RNA Holder ${ }^{\circledR}$ (BioAgency Biotecnologia; Brazil) at $-20^{\circ} \mathrm{C}$ until RNA extraction. Birds in the comfort group were sacrificed immediately after the groups were established. Of the 24 birds subjected to each temperature stress, only 12 (six from each FE group) were used for the gene expression analysis.

Total RNA was extracted using the Trizol ${ }^{\circledR}$ reagent (Invitrogen; Carlsbad, CA, USA), according to manufacturer recommendations, at a ratio of $1 \mathrm{~mL} / 100 \mathrm{mg}$ tissue. All materials were previously treated with RNase inhibitor (RNase AWAY ${ }^{\circledR}$; Invitrogen). The muscle (muscle + Trizol) was ground using an electric homogenizer (Polytron) until its complete dissociation, after which $200 \mu \mathrm{L}$ chloroform was added, and the mixture was manually stirred for $1 \mathrm{~min}$. Samples were then centrifuged for $15 \mathrm{~min}$ at $12,000 \mathrm{rpm}$ at $4{ }^{\circ} \mathrm{C}$, and the resulting liquid phase was collected and transferred to a clean tube to which $500 \mu \mathrm{L}$ isopropanol was added. Samples were again centrifuged for $15 \mathrm{~min}$ at $12,000 \mathrm{rpm}$ at $4^{\circ} \mathrm{C}$. The supernatant was discarded and the precipitate was washed with $1 \mathrm{~mL} \mathrm{75 \%} \mathrm{ethanol.} \mathrm{The} \mathrm{material} \mathrm{was} \mathrm{again}$ centrifuged at 12,000 rpm for $5 \mathrm{~min}$, and the supernatant was discarded. The resulting pellet was dried for $15 \mathrm{~min}$, and resuspended in RNase-free ultrapure water. 
Total RNA concentration was determined with the aid of a spectrophotometer at a $260 \mathrm{~nm}$ wavelength. RNA integrity was evaluated on 1\% agarose gel stained with ethidium bromide, and visualized under ultraviolet light. RNA samples were treated with DNase I (Invitrogen) to remove possible genomic DNA residues, as recommended by the manufacturer.

The SuperScript ${ }^{\mathrm{TM}}$ III First-Strand Synthesis Super Mix kit (Invitrogen Corporation; Brazil) was used to synthesize the complementary DNA (cDNA), according to manufacturer instructions. In a sterile and RNA-free tube, $6 \mu \mathrm{L}$ total RNA, $1 \mu \mathrm{L} 50 \mu \mathrm{M}$ oligo(dT) ${ }_{20}$, and $1 \mu \mathrm{L}$ annealing buffer were added. The reaction was incubated for $5 \mathrm{~min}$ at $65^{\circ} \mathrm{C}$ and then placed on ice for $1 \mathrm{~min}$. Subsequently, $10 \mu \mathrm{L} 2 \mathrm{X}$ First-Strand Reaction Mix solution and $2 \mu \mathrm{L}$ solution containing the reverse transcriptase enzyme SuperScript III and the RNAse inhibitor were added. The solution was then incubated for $50 \mathrm{~min}$ at $50^{\circ} \mathrm{C}$ for the synthesis of the cDNA. The reaction was again incubated for $5 \mathrm{~min}$ at $85^{\circ} \mathrm{C}$ and immediately placed on ice. Samples were stored at $-20^{\circ} \mathrm{C}$ until subsequent analyses.

The fluorescent compound SYBR GREEN (SYBR ${ }^{\circledR}$ GREEN PCR Master Mix, Applied Biosystems; USA) was used for real-time reverse transcription-polymerase chain reaction (RT-PCR). RT-PCR analyses were carried out in the StepOnePlus v.2.2 apparatus (Applied Biosystems). All reactions were submitted to the same analysis conditions and were normalized by the signal of the passive reference dye (ROX Reference Dye; Invitrogen) to correct any reading fluctuations caused by volume variations and evaporation during the reaction.

The ANT and COX III primers used in the reactions were designed according to OjanoDirain et al. (2007), as shown in Table 1. Two endogenous controls, the $\beta$-actin and GAPDH genes, were tested, and only the $\beta$-actin gene (accession no. L08165) was used because it was shown to be more efficient in the reaction. All analyses were carried out at a final volume of 25 $\mu \mathrm{L}$ and in duplicate. Gene expression values are expressed in arbitrary units (AU).

\begin{tabular}{lccl}
\multicolumn{2}{c}{ Table 1. qRT-PCR primers. } & & \\
\hline Gene & Amplicom (bp) & GenBank access number & Primers sequence (5'-3') \\
\hline COX III & 71 & NP_006921 & AGGATTCTATTTCACAGCCCTACAAG \\
ANT & 67 & AGACGCTGTCAGCGATTGAGA \\
$\beta$-actin & 136 & TGTGGCTGGTGTGGTTTCCTA & GCGTCCTGACTGCATCATCA \\
& & LCCCCAAAGCCAACAGA \\
& & CCAGAGTCCATCACAATACC \\
\hline
\end{tabular}

The results are shown as the mean and the standard deviation. To investigate the interactions between different temperatures and FE, the data were subjected to analysis of variance (ANOVA). A general liner model (GLM) was used to determine significant interactions between treatments. Where significant effects were detected in the ANOVA $(\mathrm{P}<0.05)$, means were compared using the Tukey test. Prior to analysis, data were checked for normality using the univariate procedure in SAS (SAS Inst. Inc.; Cary, NC, USA).

\section{RESULTS}

Quantitative RT-PCR was used to evaluate gene expression patterns in the liver and pectoralis muscle in response to different FEs and environmental temperatures. The data were 
normalized using the $\beta$-actin gene, whose expression did not change among treatment groups.

After the period of individual feed intake and weight gain evaluation, we separated the animals into two homogeneous groups: the high FE group and the low FE group. At the beginning of the FE evaluation period, the animals in both groups had statistically equal initial weights (119.55 g for high FE animals and $121.00 \mathrm{~g}$ for low FE animals). The high FE group had higher mean final weight, weight gain, and feed conversion, despite consuming the same amount of feed as low FE animals (107.00 $\mathrm{g}$ for high FE and $106.74 \mathrm{~g}$ for low FE) (Figure 1).
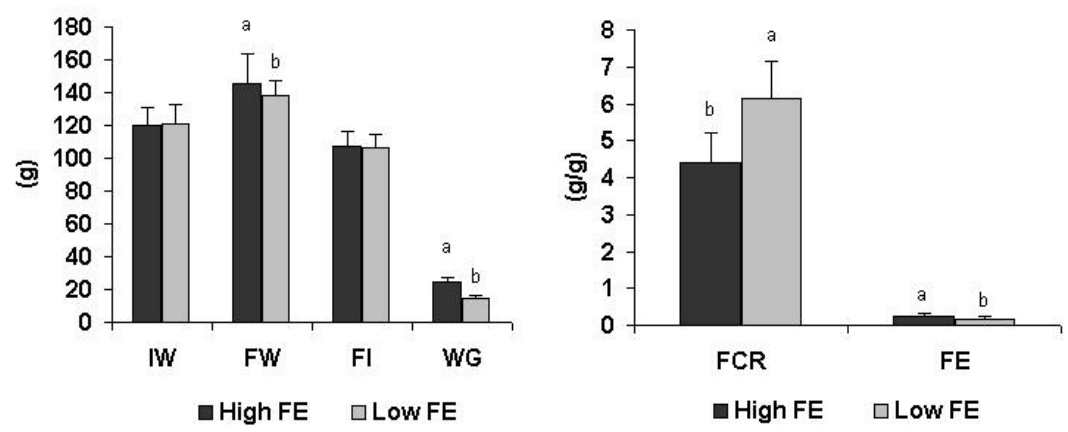

Figure 1. $\mathrm{IW}=$ initial weight; $\mathrm{FW}=$ final weight; $\mathrm{FI}=$ feed intake; $\mathrm{WG}=$ weight gain; $\mathrm{FCR}=$ feed conversion ratio; $\mathrm{FE}=$ feed efficiency of high and low-FE quails. Values are reported as means with their standard deviations represented by vertical bars. Different letters above de bars indicate statistically significant differences $(\mathrm{P}<0.05)$.

The results of the expressions of the ANT and COX III genes in the liver and muscle of high and low FE Japanese quails subjected to three environmental temperatures are shown in Table 2.

Table 2. Mitochondrial genes expression in the liver and muscle of high- and low-FE Japanese quails submitted to three environmental temperatures.

\begin{tabular}{|c|c|c|c|c|}
\hline & \multicolumn{2}{|c|}{ Liver } & \multicolumn{2}{|c|}{ Muscle } \\
\hline & ANT & COX III & ANT & COX III \\
\hline \multicolumn{5}{|l|}{ High- FE } \\
\hline Comfort & $5.83 \pm 0.24$ & $0.006 \pm 0.001$ & $6.57 \pm 2.19$ & $0.08 \pm 0.03^{b}$ \\
\hline Heat stress & $4.83 \pm 0.18$ & $0.004 \pm 0.001$ & $5.29 \pm 0.67$ & $0.10 \pm 0.02^{b}$ \\
\hline Cold stress & $5.38 \pm 0.55$ & $0.47 \pm 0.14$ & $8.80 \pm 0.75$ & $0.14 \pm 0.03^{\mathrm{a}}$ \\
\hline \multicolumn{5}{|l|}{ Low-FE } \\
\hline Comfort & $5.92 \pm 0.31$ & $0.01 \pm 0.0005$ & $8.37 \pm 0.53$ & $0.08 \pm 0.01^{\mathrm{b}}$ \\
\hline Heat stress & $4.71 \pm 0.40$ & $0.003 \pm 0.0005$ & $5.52 \pm 0.58$ & $0.06 \pm 0.02^{\mathrm{c}}$ \\
\hline Cold stress & $5.73 \pm 0.81$ & $0.37 \pm 0.18$ & $9.42 \pm 0.71$ & $0.08 \pm 0.008^{\mathrm{b}}$ \\
\hline \multicolumn{5}{|l|}{ Main effects } \\
\hline \multicolumn{5}{|l|}{ Efficiency } \\
\hline High & $5.35 \pm 0.54$ & $0.16 \pm 0.024$ & $7.77 \pm 1.79^{\mathrm{a}}$ & $0.11 \pm 0.04$ \\
\hline Low & $5.46 \pm 0.75$ & $0.13 \pm 0.020$ & $6.87 \pm 1.98^{\mathrm{b}}$ & $0.07 \pm 0.02$ \\
\hline \multicolumn{5}{|l|}{ Environment } \\
\hline Comfort & $5.88 \pm 0.29^{\mathrm{a}}$ & $0.008 \pm 0.002^{\mathrm{b}}$ & $7.47 \pm 1.78^{\mathrm{b}}$ & $0.08 \pm 0.02$ \\
\hline Heat stress & $4.77 \pm 0.27^{b}$ & $0.003 \pm 0.001^{\mathrm{b}}$ & $5.40 \pm 0.61^{\mathrm{c}}$ & $0.08 \pm 0.03$ \\
\hline Cold stress & $5.55 \pm 0.68^{\mathrm{a}}$ & $0.42 \pm 0.16^{\mathrm{a}}$ & $9.11 \pm 0.77^{\mathrm{a}}$ & $0.11 \pm 0.03$ \\
\hline \multicolumn{5}{|l|}{ Probabilities } \\
\hline Efficiency & 0.4968 & 0.2774 & 0.0196 & $<.0001$ \\
\hline Environment & $<.0001$ & $<.0001$ & $<.0001$ & 0.0006 \\
\hline Interaction & 0.4729 & 0.2782 & 0.1974 & 0.0040 \\
\hline
\end{tabular}

Values are reported as means with their standard deviations. ${ }^{\text {a,b,c }}$ Mean values within a column with different superscript letters were significantly different $(\mathrm{P}>0.05)$. 
The ANT and COX III mRNA expressions in the liver were affected only by environmental temperature. Regarding the ANT mRNA expression, lower expression of this gene was observed in animals exposed to heat stress (4.77 AU), with no difference between animals subjected to cold stress and thermal comfort. Whereas for the COX III mRNA expression, we observed that when the animals were exposed to low temperature, there was a much higher expression of this gene.

Regarding the expressions of these genes in the muscle, we observed that the ANT mRNA expression was affected by both FE and environmental temperature. High FE animals showed higher expression than low FE animals (7.77 AU vs $6.87 \mathrm{AU})$, and higher expression was also observed in animals subjected to cold stress, followed by thermal comfort, and then heat stress.

We observed a significant interaction between the effects of FE and environmental temperature on the expression of COX III mRNA in the muscle. The highest COX III mRNA expression was observed in high FE animals that were subjected to cold stress. There was no difference in COX III mRNA expression among high FE animals from the thermal comfort and heat stress groups and low FE animals from the thermal comfort and cold stress groups. Lower COX III mRNA expression was observed in the muscle of animals with low FE subjected to heat stress.

\section{DISCUSSION}

The main objective of this study was to determine whether there was any connection between the quail FE phenotype and the expression of mitochondrial genes, and to evaluate whether environmental temperature might influence the expression of such genes. After the period of individual FE evaluation, we separated the animals into two fairly homogeneous FE groups of high and low FE, since our results showed that high FE Japanese quails gained significantly more body weight, despite having a similar feed intake to those with low FE. Therefore, we hypothesized that the observed differences might be partially explained by differences in the expression of important genes that activate different metabolic mechanisms.

Our results showed that animals with greater FE also showed higher expression levels of mitochondrial genes that are known to play important roles in energy production efficiency. Several studies have demonstrated a relationship between the expression of mitochondrial genes and the FE phenotype. In this study, we also observed increased ANT and COX III mRNA expressions in high FE animals. In addition, high FE animals have also been shown to have reduced ROS production, reduced protein oxidation, increased mitochondrial respiration rates, and increased respiratory chain complexes activity, with greater coupling in the electron transport by the chain (Iqbal et al., 2004, 2005; Ojano-Dirain et al., 2007; Krueger et al., 2007; Bottje and Carstens, 2009; Kelly et al., 2011).

Besides the influence of ATP production, many other physiological systems are involved in the control of FE-related features. Metabolic pathways involved in protein deposition and in food intake control, among others, also play a key role in FE. Recent studies on muscle growth (Tesseraud et al., 2007; Zheng et al., 2011) and food intake control have shown that the body has cellular/molecular mechanisms within a single signaling pathway that function to connect peripheral tissues, where energy is used or stored, to the central nervous system, which regulates energy acquisition, by controlling the feed intake (Richards et al., 2010).

To better understand the cellular mechanisms that define the FE phenotype, Bottje 
and Kong (2013) conducted an experiment with broilers separated into groups of high and low FE in order to evaluate the overall relationship between FE and gene expression. A total of 782 genes were found to be differentially expressed between high and low FE birds. These results suggested that high FE birds exhibited increased expression of genes associated with signal transduction pathways, anabolic activities, and activities of energy coordination; and metabolic pathways that are favorable to development and cell growth. On the other hand, low FE animals showed greater expression of genes related to actin-myosin filaments and those related to or responsive to stress. Thus, the authors suggested that the low FE phenotype could result from the expression of genes modulated by oxidative stress.

Regarding the association between stress and low FE birds, other studies have found that the mitochondria of low FE poultry produced more $\mathrm{H}_{2} \mathrm{O}_{2}$, which is associated with higher protein oxidation and lower activity of the complexes of the electron transport chain (Bottje et al., 2006). These authors suggested this higher level of oxidized proteins might contribute to the low FE phenotype due to an increase in cell energy requirements for repairing such proteins, as well as the reduction or impairment of the function of the damaged proteins. Therefore, higher $\mathrm{H}_{2} \mathrm{O}_{2}$ production in poultry with low $\mathrm{FE}$ followed by protein damage may also impair the activity of mitochondrial genes.

The novelty of our study is the fact that we subjected high and low FE quails to cold and heat stress. We were motivated to investigate this effect owing to several studies that showed that environmental temperature could affect bird metabolism and even the FE phenotype (Hangalapura et al., 2004). These studies showed that changes in environmental temperature above or below the thermal comfort zone stimulated thermal-regulation physiological mechanisms that may affect animal performance to various degrees.

Stress is known to be related to neurochemical and hormonal changes, including alterations in adrenal and thyroid hormone levels (Hangalapura, 2006). In birds, the thyroid hormones are essential for the animals' normal growth since the thyrotropic axis has profound effects on development that are closely connected to the somatotropic axis. The predominant form of thyroid hormone secreted by the thyroid gland is thyroxine (T4); triiodothyronine (T3) is its active form and is derived from the hepatic monodeiodination of T4, although both T4 and T3 can be catabolized to a metabolically inactive reverse T3 (rT3) and T2 (Kim, 2010).

Several studies show that environmental temperature can affect the circulating levels of thyroid hormones. The results of these studies showed that heat stress generally decreases (Melesse et al., 2011; Willemsen et al., 2011), and cold stress generally increases the concentration of these hormones (Venditti et al., 2010). Thyroid hormones are also known to act on thermogenesis in birds. When animals are exposed to high temperatures, T4 is inactivated to rT3, whereas when birds are exposed to cold stress, T4 is converted to T3, which stimulates an increase in metabolic activity (Melesse et al., 2011).

In addition to their many functions in growth, thyroid hormones also participate in the control of ANT transcription. In mice, ANT transcription regulation occurs through of a positive muscle-specific promoter element called OXBOX, which regulates the ANT gene in muscle, and another element, REBOX, which overlaps with the OXBOX promoter element. The binding of factors to the REBOX element is regulated by environmental factors, including T3 and T4 (Chung et al., 1992; Portman, 2002).

We here observed that ANT mRNA expression was significantly lower in the liver of animals exposed to heat stress, and that in the muscle, expression of this gene occurred differentially 
among the three treatments. We observed greater ANT mRNA expression in quails subjected to cold stress, and lower expression in animals exposed to heat stress. Because thyroid hormones are needed for ANT transcription control, these expression results may be due to the fact that higher temperatures result in the reduction of $\mathrm{T} 3$ and $\mathrm{T} 4$ levels, while lower temperatures are known to increase the levels of these hormones. Thus, cold stress might have increased the levels of thyroid hormones, which, in turn, contributed to greater ANT mRNA expression in cold-stressed birds.

Environmental temperature is an important determinant of respiratory activity in different tissues, which has been shown to increase in animals subjected to low temperatures (Martin et al., 1993). In this study, we did not observe differences in COX III mRNA expression levels between animals exposed to thermal comfort and heat stress, although the highest expression level was observed in the liver and muscle of cold-stressed animals. Interestingly, there was an interaction effect between FE and temperature on the COX III mRNA expression level in the muscle, with the highest expression observed in high FE and cold-stressed animals. This result is particularly relevant owing to the great importance of the COX III gene for ATP production efficiency. Greater cytochrome c oxidase activity has previously been related to high FE birds (Iqbal et al., 2005) and to animals subjected to low temperatures (Martin et al., 1993). Some studies have also shown the negative effects of heat stress on cytochrome c oxidase activity (Ando et al., 1997), and other studies have suggested that heat shock proteins can protect the respiratory chain complexes under stressful conditions, thereby contributing to the maintenance of mitochondrial activity (Chen et al., 2004; Vogt et al., 2011).

The results obtained in this study suggest a possible correlation between the genes involved in energy production by mitochondria and the FE phenotype, and that environmental temperature affects the expression of ANT and COX III mRNA. Japanese quails presenting different FE levels respond differently to environmental stimuli.

\section{ACKNOWLEDGMENTS}

The authors are grateful to Procad-CAPES and CNPq.

\section{REFERENCES}

Ando M, Katagiri K, Yamamoto S, Wakamatsu K, et al. (1997). Age-related effects of heat stress on protective enzymes for peroxides and microsomal monooxygenase in rat liver. Environ Health Perspect 105: 726-733.

Bai Z, Harvey LM and McNeil B (2003). Elevated temperature effects on the oxidant/antioxidant balance in submerged batch cultures of the filamentous fungus Aspergillus niger B1-D. Biotechnol. Bioeng. 83: 772-779.

Blahová J, Dobsiková R, Straková E and Suchý P (2007). Effect of low environmental temperature on performance and blood system in broiler chickens (Gallus domesticus). Acta Vet. Brno 76: 17-23.

Bottje WG and Carstens GE (2009). Association of mitochondrial function and feed efficiency in poultry and livestock species. J. Anim. Sci. 87: E48-E63.

Bottje W and Kong BW (2013). Cell Biology Symposium: feed efficiency: mitochondrial function to global gene expression. J. Anim. Sci. 91: 1582-1593.

Bottje W, Pumford NR, Ojano-Dirain C, Iqbal M, et al. (2006). Feed efficiency and mitochondrial function. Poult. Sci. 85: 8-14.

Chen HW, Kuo HT, Lu TS, Wang SJ, et al. (2004). Cytochrome c oxidase as the target of the heat shock protective effect in septic liver. Int. J. Exp. Pathol. 85: 249-256.

Chung AB, Stepien G, Haraguchi Y, Li K, et al. (1992). Transcriptional control of nuclear genes for the mitochondrial muscle ADP/ATP translocator and the ATP synthase beta subunit. Multiple factors interact with the OXBOX/ REBOX promoter sequences. J. Biol. Chem. 267: 21154-21161.

Hangalapura BN (2006). Cold Stress and Immunity: Do Chickens Adapt to cold by Trading-off Immunity for Thermoregulation. 
PhD-Thesis. Wageningen Institute of Animal Sciences, Wageningen University and Research Centre.

Hangalapura BN, Nieuwland MG, Buyse J, Kemp B, et al. (2004). Effect of duration of cold stress on plasma adrenal and thyroid hormone levels and immune responses in chicken lines divergently selected for antibody responses. Poult. Sci. 83: 1644-1649.

Iqbal M, Pumford NR, Tang ZX, Lassiter K, et al. (2004). Low feed efficient broilers within a single genetic line exhibit higher oxidative stress and protein expression in breast muscle with lower mitochondrial complex activity. Poult. Sci. 83: 474-484.

Iqbal M, Pumford NR, Tang ZX, Lassiter K, et al. (2005). Compromised liver mitochondrial function and complex activity in low feed efficient broilers are associated with higher oxidative stress and differential protein expression. Poult. Sci. 84: 933-941.

Kelly AK, Waters SM, McGee M, Fonseca RG, et al. (2011). mRNA expression of genes regulating oxidative phosphorylation in the muscle of beef cattle divergently ranked on residual feed intake. Physiol. Genomics 43: 12-23.

Kemp TJ, Causton HC and Clerk A (2003). Changes in gene expression induced by $\mathrm{H}_{2} \mathrm{O}_{2}$ in cardiac myocytes. Biochem. Biophys. Res. Commun. 307: 416-421.

Kim JW (2010). The endocrine regulation of chicken growth. Asian - Aust. J. Anim. Sci. 23: 1668-1676.

Krueger WK, Carstens GE, Lancaster PA, Brown EG, et al. (2007). Relationships between residual feed intake and dry matter digestibility in growing calves. J. Anim. Sci. 85 (Suppl 2): 30.

Lee HC and Wei YH (2005). Mitochondrial biogenesis and mitochondrial DNA maintenance of mammalian cells under oxidative stress. Int. J. Biochem. Cell Biol. 37: 822-834.

Martin I, Vinas O, Mampel T, Iglesias R, et al. (1993). Effects of cold environment on mitochondrial genome expression in the rat: evidence for a tissue-specific increase in the liver, independent of changes in mitochondrial gene abundance. Biochem. J. 296 (Pt 1): 231-234.

Melesse A, Maak S, Schmidt R and Von Lengerken G (2011). Effect of long-term heat stress on key enzyme activities and T3 levels in commercial layer hens. Int. J. Livestock Prod. 2: 107-116.

Moustafa MH, Sharma RK, Thornton J, Mascha E, et al. (2004). Relationship between ROS production, apoptosis and DNA denaturation in spermatozoa from patients examined for infertility. Hum. Reprod. 19: 129-138.

Mujahid A, Yoshiki Y, Akiba Y and Toyomizu M (2005). Superoxide radical production in chicken skeletal muscle induced by acute heat stress. Poult. Sci. 84: 307-314.

Mujahid A, Akiba Y and Toyomizu M (2009). Olive oil-supplemented diet alleviates acute heat stress-induced mitochondrial ROS production in chicken skeletal muscle. Am. J. Physiol. Regul. Integr. Comp. Physiol. 297: R690-R698.

Nelson DL and Cox MM (2008). Lehninger Principles of Biochemistry. Worth Publishers, New York.

Ojano-Dirain C, Toyomizu M, Wing T, Cooper M, et al. (2007). Gene expression in breast muscle and duodenum from low and high feed efficient broilers. Poult. Sci. 86: 372-381.

Pinto R, Ferreira AS, Donzele JL, Albino LFT, et al. (2003). Exigência de metionina mais cistina para codornas japonesas em crescimento. Braz. J. Anim. Sci. 32: 1174-1181.

Portman MA (2002). The adenine nucleotide translocator: regulation and function during myocardial development and hypertrophy. Clin. Exp. Pharmacol. Physiol. 29: 334-338.

Richards MP, Rosebrough RW, Coon CN and McMurtry JP (2010). Feed intake regulation for the female broiler breeder: In theory and in practice. J. Appl. Poultry Res. 19: 182-193.

Rostagno HS, Albino LFT, Donzele JL and Gomes PC (2011). Tabelas Brasileiras para aves e Suínos - Composição de Alimentos e Exigências Nutricionais. 3rd edn. Universidade Federal de Viçosa, Viçosa.

Schauss AC, Huang H, Choi SY, Xu L, et al. (2010). A novel cell-free mitochondrial fusion assay amenable for highthroughput screenings of fusion modulators. BMC Biol. 8: 100.

Tesseraud S, Métayer-Coustard S, Boussaid S, Crochet S, et al. (2007). Insulin and amino acid availability regulate atrogin-1 in avian QT6 cells. Biochem. Biophys. Res. Commun. 357: 181-186.

Venditti P, Di Stefano L and Di Meo S (2010). Oxidative stress in cold-induced hyperthyroid state. J. Exp. Biol. 213: 2899-2911.

Vogt S, Portig I, Irqsusi M, Ruppert V, et al. (2011). Heat shock protein expression and change of cytochrome c oxidase activity: presence of two phylogenic old systems to protect tissues in ischemia and reperfusion. J. Bioenerg. Biomembr. 43: 425-435.

Willemsen H, Swennen Q, Everaert N, Geraert PA, et al. (2011). Effects of dietary supplementation of methionine and its hydroxy analog DL-2-hydroxy-4-methylthiobutanoic acid on growth performance, plasma hormone levels, and the redox status of broiler chickens exposed to high temperatures. Poult. Sci. 90: 2311-2320.

Yahav S (2000). Domestic fowl-strategies to confort evironmental conditions. Avian Poultry Biol. Rev. 11: 811-95.

Zheng Q, Zhang Y, Chen Y, Yang N, et al. (2009). Systematic identification of genes involved in divergent skeletal muscle growth rates of broiler and layer chickens. BMC Genomics 10: 87. 